Marshall Hall, that his citing cases resembles a quack advertisement, we find this immaculate gentleman saying, in the very next page, because Dr. Hall did not deem it necessary to cite cases in support of his opinions on another point, "All this is apparently theoretical; if Dr. Hall can produce cases in which he has so applied the stays, and successfully, we trust that he will do so:" and, as though he feared the public would not sufficiently appreciate the unjust and ungemerous insinuation, he adds, "A reference to the general practitioners in attendance, whom he is always so careful to name, will suffice"! Did this gentleman ever read the fable of "the old man and his ass"?--if not, I take the liberty of directing his attention to it, as well as to that of "the dog in the manger," or "the fox and the grapes." The false reviewer absolutely condescends to write an essay on Dr. Hall's temper; did he ever study his own? I can fancy what were the feelings of delight in the editor, when the article on Dr. Hall's "Observations" was brought to him, but I do not envy him his enjoyment while gloating in private over this production; and let me tell him, it will blast his scientific character for ever. If he had conducted his Review impartially, and with a due care to the honour of his profession, he and it would have lived revered. But what now is the case? $\Pi$ e is despised for his partiality, disliked for his ungenerous and shabby conduct, and necessarily regarded in the provinces as a mere tool for those behind the curtain to work by. It would have been far better for Dr. Forbes, "far better for his happiness" had he never emerged from the situation which he held in his youth; it would most assuredly have been far better for his reputation and his finances had he never courted courtly favours, or even had he remained contented with his lot at Chichester. What cau we expect of such men as the disappointed editors of this Medical Review, but that which they have done by virtue of their Scottish or Clannish connexion? They have published a book, in which they praise abundantly their own writings, their own labours, and their own acts. Witness the superaboundings of praise lavished upon Dr. Carpenter's last student's volume, and compare it with the abuse heaped upon the head of Marshall Hall, or with the stinted meed of praise acceded to Erasmus Wilson and others. I believe it wonld be a rare thing for a person not connected with the clique to have his work reviewed impartially; but as to their oun works, they are always puffed as nonpareils. Before the sheets of the books are dry the laudatory articles are ready; and why? Because they have been prepared beforehand. Let them answer to the world who wrote the article on Mr. Noble's work on the Brain, in which Dr. Carpenter's opinions are quoted, supported, and maintained? Look at the review of the book of another of their writers, Dr. Walsh, on Cancer. This was actually lauded in three laborious articles in three successive numbers of a Quarterly Review. Dr. Walsh positively had his trumpet sounded in a blast of three quarters of a year's length! Surely such a thing is unparalleled in the history of quarterlies. But, Mr. Editor, there is another view to be taken of this matter, and that is an important one in book-making, for it is a pecuniary one a slashing article is eagerly sought after ; they evidently wish "to rise on the great man's shoulder," and then to be able to say, with the fy on the wheel, "what a dust we are making." It is said Lord Brougham is worth a thousand a year to Punch, and that the Bishop of Exeter is as good as five hundred a year to the editor of a local paper in Exeter, and who knows but that the editor of the Review in question is making a marketable commodity of Dr. M. Hall, seeing that abuse of this great physiologist is one of the constant leading topics in his work, which begins by praising the ostensible editor, and is silled witl loathsome adulations of its own contributors, and which has but one end in view, their own personal aggrandizement.

Plymouth, January, 1847 . Yours, Mr. Editor, very truly, JUSTITIA.

\section{THE MAGNETIC POLE.}

\section{To the Editor of The Lavoet.}

Sn,-In your insertion of my communication, in your journal of Jan. 9th, you have appended a note, to the effect that one of the statements therein contained was deficient in positive evidence. This romark was perfectly justifiable, though, at the same time, the position I there advanced remains intact. A misunderstanding has evidently arisen, in consequence of my omission of the word "magnetic." I was alluding to the pole, in reference to the magnetic equator, and therefore it is easy to see that it was the magnetic, and not the terrestrial, pole, which was intended. The following extract from "Sir John Ross's Voyage to the Polar Regions" will show that my assertion was not deficient in either positive or practical evidence:-

"The place of the observatory was as near to the magnetic pole as the limited means which I possessed enabled me to determine. The amount of dip, as indicated by my dippingneedle, was $89^{\circ} 59^{\prime}$, being thus within one minute of the vertical; while the proximity at least of this pole, if not its actual existence where we stood, was further confirmed by the action, or rather, the total inaction, of the several horizontal needles then in my profession. These were suspended in the most delicate manner possible, but there was not one which showed the slightest effort to move from the position in which it was placed; a fact which even the most moderately informed of readers must now know to be one which proves that the centre of attraction lies at a very small horizontal distance, if at any."

As a want of evidence for any of the facts which form the basis of a theory must materially deteriorate its value, your insertion of this explanation will be esteemed a favour. I am a ware that the blame of the misunderstanding must be charged upon my carelessness in omitting to specify the nature of the pole I was alluding to.-I am, Sir, your obedient servant, J. W. LAkE.

P.S.-The position of this pole is, in lat. $70^{\circ} 5^{\prime} 17^{\prime \prime}$ N., and Ion. $96^{\circ} 46^{\prime} 45^{\prime \prime}$ West. Its discovery took place during the reign of his late Majesty, and it was formally taken possession of in his name.

Holbeach, Jan. 1847.

\section{NARCOTISM FROM SUCKING OPIUM LOZENGES. To the Editor of The LANCET.}

Sir,-On Tuesday evening, the 29th December, 1846, I was summoned hastily to visit Mr. E. R-, the landlord of an inn in this town. On arrival at his house I found him sitting in the bar; his neckcloth had been removed, and his waistcoat thrown open. His countenance was deadly pale-there was extreme somnolence, and it was with difficulty any reply to a question could be elicited. The pupils at this time were contracted, the breathing heavy and oppressed, occasionally stertorous, the pulse small and feeble.

On inquiry $I$ ascertained that at one o'clock in the afternoon he had visited a druggist's shop, and had purchased two ounces of piped opium lozenges, for the purpose of allaying a cough which annoyed him. The lozenges were wrapped up in paper and delivered, without any particular directions or caution as to the mode of taking them. The gentleman repaired to lis own house and commenced sucking the lozenges, continuing to do so, without intermission, during the whole of the afternoon, until seven o'clock. It was remarked by one or two friends who sat with him, that he was uncommonly stupid, but they had no suspicion that the lozenges were producing this effect. Eventually, he became extremely sleepy, and ceased to take any part in conversation. At ten minutes past seven, P.M., I was sent for, and found him in the condition above described. In a tumbler glass I was shown the remainder of the lozenges, very few of which were left. He must have sucked about one ounce and a half. At this time I did not know the exact composition of the lozenges, though, from the symptoms, it was tolerably clear that a powerful narcotic had been taken. I took two or three of the lozenges, and went to the druggist whose shop was close at hand: all that $I$ could learn was, that they contained opium, but the vendor did not know how much. He could give me no idea as to the quantity in each, at which I expressed my surprise. On returning to my patient I immediately administered a scruple of sulphate of zinc, and in ten minutes repeated the dose, with free libation of warm water. After waiting a little time, and there being no disposition to vomit, I determined, without further delay, to empty the stomach. I passed the tube of the stomach-pump and drew off a considerable quantity of dark, coffee-coloured fluid; then injected two pints of clean warm water, which returned, still of a brownish colour. The stomach was injected again with water, and this time it returned nearly clear. The tube was withdrawn, and the patient now drank a small basonful of strong coffee without sugar or milk, and this was repeated in smaller quantities at intervals. Ile took an ounce of the following mixture every half hour for three doses, after this, every two hours: compound spirits of ammonia, three drachms, chloric ether, one drachm, water, for six ounces. The legs were enveloped in flannels wrung out of hot water and sprinkled freely with turpentine. By dint of persevering efforts he was kept awake, and by three o'clock 